Polymer Journal, Vol. 39, No. 7, pp. 675-683 (2007)

(C) 2007 The Society of Polymer Science, Japan

\title{
Triarylamine-Bearing Poly(1,4-phenylenevinylene): Facile Preparation and Its Durable Aminium Polyradical
}

\author{
Takashi KuRATA, Yong-Jin Pu, and Hiroyuki NISHIDE ${ }^{\dagger}$ \\ Department of Applied Chemistry, Waseda University, 3-4-1, Okubo, Shinjuku-ku, Tokyo 169-8555, Japan
}

(Received February 1, 2007; Accepted March 25, 2007; Published May 16, 2007)

\begin{abstract}
Poly[2-\{bis(4-methoxyphenyl)amino\}phenyl-5-(2-ethylhexyloxy)-1,4-phenylenevinylene] 1 was prepared via the Gilch reaction of the $p$-bis(chloromethyl)benzene monomer, 2-\{bis(4-methoxyphenyl)aminophenyl $\}-\alpha, \alpha^{\prime}$-dichloro- $p$-xylene. The Gilch reaction facilitated the preparation of the polyphenylenevinylene with a triarylamine pendant group when compared to that via the Heck polycondensation. The molecular weight of the polymer was approximately $4.0 \times 10^{5}$, and it was soluble in common solvents and was reversibly redoxed due to the pendant arylamine moiety. Chemical oxidation of $\mathbf{1}$ afforded the corresponding aminium polyradical $\mathbf{1}^{+}$with the half life-time of $c a .2$ weeks under ambient conditions. ESR and magnetization measurements of $\mathbf{1}^{+}$revealed a forbidden multiplet signal and an average spin quantum number $(S)$ of $3 / 2$ at low temperature, respectively. The polyradical $\mathbf{1}^{+}$was the first example of a high molecular weight, high-spin organic polymer with solvent-solubility and film formability. 2,3$\operatorname{Bis}[N, N$-bis(4-methoxyphenyl)aminophenyl $]$ stilbene $\mathbf{2}$ and its aminium diradical $\mathbf{2}^{+}$were also prepared as the model dimer compounds; $\mathbf{2}^{+}$was a triplet molecule at low temperature. The effect of the $\pi$-conjugated poly(1,4-phenylenevinylene) backbone on the high-spin alignment was also discussed. [doi:10.1295/polymj.PJ2006226]

KEY WORDS Poly(phenylenevinylene) / Gilch Reaction / Aminium Radical / High-Spin Molecule / $\pi$-Conjugated Polymer / Radical Polymer /
\end{abstract}

$\pi$-Conjugated and high-spin radical polymers have drawn the attention of researchers due to the possible creation of a purely organic-derived magnetic material. ${ }^{1,2}$ The target radical polymers have been molecular-designed by satisfying a non-Kekulé and nondisjoint fashion upon the $\pi$-conjugated connectivity among the radical moieties in order to realize an effective overlap of singly occupied molecular orbitals and a strong ferromagnetic interaction of the unpaired electrons of the radical moieties. ${ }^{1,3}$ Rajca et al. synthesized a two-dimensionally macrocyclic polyradical, poly(1,3-phenylenephenylmethine), and succeeded in producing very high magnetic moments and a spin quantum number $(S>5400)$ at very low temperature ${ }^{4}$ However, the arylmethine radical did not exist above $200 \mathrm{~K}$, which prevents further development of the high-spin organic polymer.

A triarylaminium radical possesses a high durability under ambient conditions due to the delocalized unpaired electron, which could also contribute to an efficient spin-exchange interaction in the molecule. Recently, we succeeded in synthesizing a durable poly(1,2-phenylenevinylene anisylaminium) derivative with a molecular weight of several thousands, in which the stilbene linker worked as an effective ferromagnetic spin coupler through the extended $\pi$-conjugated structure to give $S$ of 3/2-7/2 at room temperature. ${ }^{5,6}$ Such durable radical-bearing $\pi$-conjugated polymers possess a solvent solubility and tolerance for the spin-defect because the pendant spins are expected to interact not only with neighboring, but also with discrete spins. ${ }^{1 \mathrm{c}, 6-11}$ For the backbone $\pi$-conjugated structure, poly(phenylenevinylene)s are known to possess an extended $\pi$-conjugation, ${ }^{12}$ and are characterized as being coplanar with an extended $\pi$-conjugation even after the introduction of pendant groups. We have reported high-spin poly(1,2-phenylenevinylene)s bearing stable radical moieties such as 3,5-di-tbutyl-4-oxyphenyl, ${ }^{8} \mathrm{~N}$-t-butylnitroxide, ${ }^{9}$ and nitronyl nitroxide. ${ }^{10}$ Both the regioregularity or head-to-tail linkage of the backbone and high molecular weight are important factors for achieving a high $S$ value ${ }^{1,2}$ because the former induces a ferromagnetic interaction between the pendant spin sources by satisfying the non-Kekule fashion and the latter increases the number of spin sources on one polyradical molecule. However, the poly(1,4-phenylenevinylene) bearing a durable radical moiety has not yet been reported.

Poly(1,4-phenylenevinylene)s could possess a solvent-solubility and film formability by substituting an alkyl chain, which has been explored as a functional material for applications in organic light-emitting diodes, ${ }^{13}$ photovoltaic cells,${ }^{14}$ and photorefractive materials. ${ }^{15}$ Alkyl-substituted and high molecular-weight poly(1,4-phenylenevinylene)s have been prepared via the appropriate polymerization routes. The high molecular weight and aminium radical-substituted poly(1,4-phenylenevinylene)s are expected to be a new

${ }^{\dagger}$ To whom correspondence should be addressed (Tel: +81-3-3200-2669, Fax: +81-3-3209-5522, E-mail: nishide@waseda.jp). 
class of electronic functional materials, e.g., a highspin and durable organic polymer and a hole-transporting polymer for light-emitting diodes. ${ }^{16}$

The polymerization routes for the poly $(1,4-$ phenylenevinylene)s are as follows: the Heck reaction, the Wittig condensation, and the Gilch reaction. The Heck reaction $^{17}$ of a bromostyrene derivative in the presence of a palladium-phosphine catalyst yields highly regioregular substituted poly(1,4-phenylenevinylene)s, but their molecular-weights often remains the oligomeric one. The Wittig-type copolymerization ${ }^{18}$ of a bisaldehyde and a bis(triphenylphosphonium)methylbromide derivative produces 1,4-phenylenevinylene polymers. However, this route requires tedious steps for the preparation of the monomers, and a bulky substituent on the monomers often prevents the polymerization. The Gilch reaction of bis(halogenomethyl)benzenes ${ }^{16}$ gives poly(1,4-phenylenevinylne)s with high molecular-weights without any metal catalyst, while the polymers often lack a regioregularity of the substitutent groups. There have been two reports regarding the Gilch polycondensation of relatively bulky group-substituted $p$-bis(halogenomethyl)benzenes to yield the poly(1,4-phenylenevinylene)s. ${ }^{19}$

Here, we, for the first time, describe the synthesis of a high-molecular weight and triarylamine-bearing poly(1,4-phenylenevinylene), poly[2-\{bis(4-methoxyphenyl)amino\} phenyl-5-(2-ethylhexyloxy)-1,4-phenylenevinylene] 1 via the Gilch reaction, which afforded the highly-regioregular phenylenevinylene backbone with the bulky pendant substituents. The magnetic property and spin alignment in its durable aminium polyradical $\mathbf{1}^{+}$was also discussed in comparison to the dimer model, 2,3-bis[ $N, N$-bis(4-methoxyphenyl)aminiumphenyl]stilbene $\mathbf{2}^{+}$.

\section{EXPERIMENTAL}

Pinacol[4-\{N,N-bis(4-methoxyphenyl)amino\}phenyl]boronate 4

A $1.56 \mathrm{M} n$-butyllithium in hexane solution $(0.56$

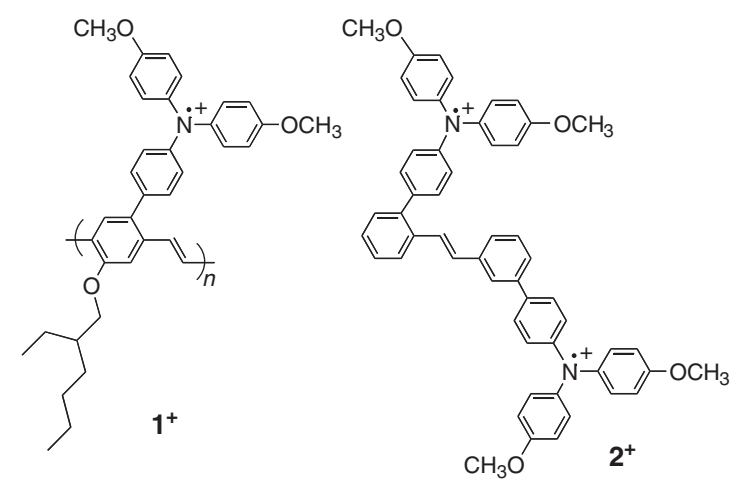

Chart 1.
$\mathrm{mL}, 0.873 \mathrm{mmol}$ ) was added dropwise to $\mathrm{N}, \mathrm{N}$-bis(4methoxyphenyl)-4-bromophenylamine ${ }^{20} \mathbf{3}(0.308 \mathrm{~g}$, $0.799 \mathrm{mmol})$ in dry THF $(15.6 \mathrm{~mL})$ at $-78^{\circ} \mathrm{C}$ and stirred for $1 \mathrm{~h}$ under nitrogen atmosphere. The mixture was transferred to a dried THF solution $(1.98 \mathrm{~mL})$ of triisopropylborate $(0.89 \mathrm{~mL}, 5.81 \mathrm{mmol})$ at $-78^{\circ} \mathrm{C}$, and then the reaction mixture was stirred for $2 \mathrm{~h}$. After the mixture was allowed to warm to room temperature, pinacol $(0.656 \mathrm{~g}, 5.55 \mathrm{mmol})$ was added and stirred for $16 \mathrm{~h}$. The solvent was removed and the residue was dissolved in hexane/dichloromethane (2/1). The filtrate was concentrated and purified by flash column chromatography (silica gel deactivated with triethylamine, hexane/dichloromethane $=10 / 1$ ) to give a pale yellow solid of $4(0.326 \mathrm{~g})$. Yield $95 \% .{ }^{1} \mathrm{H}$ NMR $\left(\mathrm{CDCl}_{3}, 500 \mathrm{MHz} ; \mathrm{ppm}\right) \delta 7.60(\mathrm{~d}, J=8.9 \mathrm{~Hz}, 2 \mathrm{H})$, $7.06(\mathrm{~d}, J=9.0 \mathrm{~Hz}, 4 \mathrm{H}), 6.86(\mathrm{~d}, J=8.7 \mathrm{~Hz}, 2 \mathrm{H})$, $6.83(\mathrm{~d}, J=8.9 \mathrm{~Hz}, 4 \mathrm{H}), 3.79(\mathrm{~s}, 6 \mathrm{H}), 1.32(\mathrm{~s}$, $12 \mathrm{H}) ;{ }^{13} \mathrm{C}$ NMR $\left(\mathrm{CDCl}_{3}, 125 \mathrm{MHz} ; \mathrm{ppm}\right) \delta 156.2$, 151.4, 140.4, 135.7, 127.1, 118.7, 114.7, 83.4, 55.5, 24.9, 24.8; MS (EI) m/e $431\left[\mathrm{M}^{+}\right], 431.3$ (calcd); Anal. Calcd for $\mathrm{C}_{26} \mathrm{H}_{30} \mathrm{BNO}_{4}$ : C, 72.3\%; H, 6.7\%; $\mathrm{N}, 7.0 \%$. Found: $\mathrm{C}, 72.4 \% ; \mathrm{H}, 7.0 \%$;, $6.8 \%$.

\section{2,3'-Bis[N,N-bis(4-methoxyphenyl)aminophenyl]stil- bene 2}

2,3'-Dibromostilbene 5 (318 $\mathrm{mg}, 0.941 \mathrm{mmol})$, the bis(4-methoxyphenylamino)phenyl-boronic ester $\mathbf{4}$ $(0.855 \mathrm{~g}, 1.98 \mathrm{mmol})$, potassium phosphate $(599 \mathrm{mg}$, $2.82 \mathrm{mmol}$ ), and tetrakis(triphenylphosphine)palla$\operatorname{dium}(0)(44 \mathrm{mg}, 0.038 \mu \mathrm{mol})$ were added to $5.6 \mathrm{~mL}$ of DMF, and then the mixture was stirred for $10 \mathrm{~h}$ at $100^{\circ} \mathrm{C}$ under nitrogen. The mixture was dissolved in dichloromethane and washed with water. The organic layer was then dried over anhydrous sodium sulfate. After removal of the solvent, the crude product was purified by flash column chromatography on silica gel (hexane/dichloromethane $=2 / 1$ ) to give a yellowish powder of $2(0.236 \mathrm{~g})$. Yield: $32 \%$. ${ }^{1} \mathrm{H}$ NMR $\left(\mathrm{CDCl}_{3}, 500 \mathrm{MHz} ; \mathrm{ppm}\right) \delta 7.72(\mathrm{~d}, J=8.0 \mathrm{~Hz}, 1 \mathrm{H})$, $7.57(\mathrm{br}, 1 \mathrm{H}), 7.41(\mathrm{~d}, 8.50 \mathrm{~Hz}, 2 \mathrm{H}), 7.36-7.30(\mathrm{~m}$, $8 \mathrm{H}), 7.19(\mathrm{~d}, J=8.6 \mathrm{~Hz}, 2 \mathrm{H}), 7.09-7.07(\mathrm{~m}, 8 \mathrm{H})$, $6.99(\mathrm{~d}, J=6.7 \mathrm{~Hz}, 2 \mathrm{H}), 6.95(\mathrm{~d}, J=6.7 \mathrm{~Hz}, 2 \mathrm{H})$, 6.83-6.79 (m, 8H), 3.78 (s, 6H), 3.75 (s, 6H); FABMS $m / z 786.6\left[\mathrm{M}^{+}\right], 786.9$ (calcd); Anal. Calcd for $\mathrm{C}_{54} \mathrm{H}_{46} \mathrm{~N}_{2} \mathrm{O}_{4}$ : C, 82.4\%; H, 5.9\%; N, 3.6\%. Found: C, $82.0 \% ; \mathrm{H}, 5.7 \% ; \mathrm{N}, 3.5 \%$.

2-[4-\{N,N-bis(4-methoxyphenyl)amino\}phenyl]-5-(2ethylhexyloxy)terephthalaldehyde 7

2-Bromo-5-(2-ethylhexyloxy)terephthalaldehyde ${ }^{16}$ $6(1.50 \mathrm{~g}, 4.39 \mathrm{mmol})$, the boronic ester $4(2.65 \mathrm{~g}, 6.14$ $\mathrm{mmol})$, and potassium phosphate $(1.40 \mathrm{~g}, 6.60 \mathrm{mmol})$ were dissolved in DMF $(26.3 \mathrm{~mL})$. Tetrakis(triphenylphosphine)palladium $(0)(0.10 \mathrm{mg}, 0.087 \mathrm{mmol})$ was 
added and reacted at $110^{\circ} \mathrm{C}$ for $17 \mathrm{~h}$. The extract with dichloromethane was washed with brine and dried on sodium sulfate. The crude product was purified by chromatography on silica gel (hexane/dichloromethane $=2 / 1)$ to afford an orange oil of $7(1.33 \mathrm{~g})$. Yield 54\%. ${ }^{1} \mathrm{H}$ NMR $\left(\mathrm{CDCl}_{3}, 500 \mathrm{MHz} ; \mathrm{ppm}\right) \delta 10.59$ $(\mathrm{s}, 1 \mathrm{H}), 10.48(\mathrm{~s}, 1 \mathrm{H}), 7.92(\mathrm{~s}, 1 \mathrm{H}), 7.56(\mathrm{~s}, 1 \mathrm{H}), 7.13-$ $6.85(\mathrm{~m}, 12 \mathrm{H}), 4.08(\mathrm{dd}, J=5.6,1.7 \mathrm{~Hz}, 2 \mathrm{H}), 3.81(\mathrm{~s}$, $6 \mathrm{H}), 1.83-1.82(\mathrm{~m}, 1 \mathrm{H}), 1.55-1.33(\mathrm{~m}, 8 \mathrm{H}), 0.98-0.90$ $(\mathrm{m}, 6 \mathrm{H}) ;{ }^{13} \mathrm{C}$ NMR $\left(\mathrm{CDCl}_{3}, 125 \mathrm{MHz} ; \mathrm{ppm}\right) \delta 192.3$, $189.5,160.0,156.4,144.4,140.4,138.2,130.8,130.7$, $128.1,127.6,127.0,119.5,114.9,110.7,100.6,71.4$, 55.5, 39.4, 30.6, 29.1, 24.0, 23.0, 14.0, 11.2; MS (EI) $\mathrm{m} / \mathrm{e} 566\left[\mathrm{M}^{+}\right], 565.7$ (calcd); Anal. Calcd for $\mathrm{C}_{36} \mathrm{H}_{39} \mathrm{NO}_{5}: \mathrm{C}, 76.4 \%$; $\mathrm{H}, 7.0 \%$; N, 2.5\%. Found: $\mathrm{C}$, $76.1 \%$; H, $6.7 \%$; N $2.4 \%$.

\section{1,4-Bis(hydroxymethyl)-2-[4-\{N,N-bis(4-methoxyphen- yl)aminolphenyl]-5-(2-ethylhexyloxy)benzene 8}

A solution of the terephthalaldehyde $7(0.850 \mathrm{~g}$, $1.50 \mathrm{mmol})$ in dry THF $(10 \mathrm{~mL})$ was added dropwise to a suspension of lithium aluminium hydride $(0.120 \mathrm{~g}, 3.16 \mathrm{mmol})$ in dry $\mathrm{THF}(4.0 \mathrm{~mL})$ at $0{ }^{\circ} \mathrm{C}$. The solution was stirred at room temperature for $0.5 \mathrm{~h}$, and then a small amount of ethyl acetate and water was carefully added to the solution. The solution was extracted with dichloromethane, and the organic layer was then washed with water, dried, and evaporated to give a white solid of $8(0.84 \mathrm{~g})$. Yield 98\%. ${ }^{1} \mathrm{H} \mathrm{NMR}\left(\mathrm{CDCl}_{3}, 500 \mathrm{MHz} ; \mathrm{ppm}\right) \delta 7.19$ (s, $1 \mathrm{H}), 7.11-6.82(\mathrm{~m}, 13 \mathrm{H}), 4.70(\mathrm{~s}, 2 \mathrm{H}), 4.66(\mathrm{~s}, 2 \mathrm{H})$, $3.98(\mathrm{dd}, J=5.5,1.5 \mathrm{~Hz}, 2 \mathrm{H}), 3.80(\mathrm{~s}, 6 \mathrm{H}), 2.31$, $2.03(\mathrm{~s}, 2 \mathrm{H}), 1.78-1.75(\mathrm{~m}, 1 \mathrm{H}), 1.62-1.24(\mathrm{~m}, 8 \mathrm{H})$, $0.97-0.90(\mathrm{~m}, 6 \mathrm{H}) ;{ }^{13} \mathrm{C} \mathrm{NMR}\left(\mathrm{CDCl}_{3}, 125 \mathrm{MHz}\right.$; ppm) $\delta 156.4,155.9,147.8,140.9,138.7,133.2$, $132.0,130.4,129.8,128.4,126.7,120.0,114.8$, $110.7,70.5,63.3,62.1,55.5,39.5,30.8,29.1,24.2$, 23.0, 14.0, 11.2; MS (EI) $m / e ~ 570\left[\mathrm{M}^{+}\right], 569.7$ (calcd); Anal. Calcd for $\mathrm{C}_{36} \mathrm{H}_{43} \mathrm{NO}_{5}: \mathrm{C}, 75.9 \%$; $\mathrm{H}$, 7.6\%; N, 2.5\%. Found: C, 75.7\%; H, 7.3\%; N, 2.3\%.

\section{1,4-Bis(chloromethyl)-2-[4-\{N,N-bis(4-methoxyphen- yl)aminolphenyl]-5-(2-ethylhexyloxy)benzene 9}

Triphenylphosphine $(1.18 \mathrm{~g}, 4.49 \mathrm{mmol})$ was suspended in $0.5 \mathrm{~mL}$ of tetrachloromethane $(5.27 \mathrm{mmol})$. To the mixture a solution of $8(0.492 \mathrm{~g}, 0.864 \mathrm{mmol})$ in toluene $(5 \mathrm{~mL})$ was added and refluxed for $14 \mathrm{~h}$. The reaction mixture was then extracted with dichloromethane. The organic layer was washed with water, dried, and evaporated. The residue was purified by chromatography with hexane/dichloromethane $(1 / 3)$ to afford a colorless oil of $9(0.300 \mathrm{~g})$. Yield $57 \%$. ${ }^{1} \mathrm{H} \mathrm{NMR}\left(\mathrm{CDCl}_{3}, 500 \mathrm{MHz} ; \mathrm{ppm}\right) \delta 7.27(\mathrm{~s}$, $1 \mathrm{H}), 7.18-7.16(\mathrm{~m}, 2 \mathrm{H}), 7.13(\mathrm{~s}, 1 \mathrm{H}), 7.07-6.83(\mathrm{~m}$, $10 \mathrm{H}), 4.66(\mathrm{~s}, 2 \mathrm{H}), 4.59(\mathrm{~s}, 2 \mathrm{H}), 4.01(\mathrm{~d}, J=5.2$
$\mathrm{Hz}, 2 \mathrm{H}), 3.75$ (s, 6H), 1.79 (m, 1H), 1.62-1.34 (m, $8 \mathrm{H}), \quad 0.99-0.91(\mathrm{~m}, 6 \mathrm{H}) ;{ }^{13} \mathrm{C} \mathrm{NMR}\left(\mathrm{CDCl}_{3}, 125\right.$ $\mathrm{MHz} ;$ ppm) $\delta$ 157.4, 157.2, 149.2, 141.7, 137.5, $135.1,133.1,132.3,130.5,127.6,127.4,120.5$, 115.5, 113.9, 71.1, 55.6, 45.3, 41.7, 40.7, 31.6, 30.0, 24.9, 24.0, 14.4, 11.6; MS (EI) $m / e \quad 605\left[(\mathrm{M}-1)^{+}\right]$, $607\left[(\mathrm{M}+1)^{+}\right], \quad 606.6$ (calcd); Anal. Calcd for $\mathrm{C}_{36} \mathrm{H}_{41} \mathrm{Cl}_{2} \mathrm{NO}_{3}$ : C, 71.3\%; H, 6.8\%; N, 2.3\%. Found: $\mathrm{C}, 71.1 \% ; \mathrm{H}, 6.7 \% ; \mathrm{N}, 2.1 \%$.

\section{2,4-Dibromo-5-octyloxybenzylalcohol 11}

A carbon tetrachloride solution $(1.77 \mathrm{~L})$ of $2,4-$ dibromo-5-octyloxytoluene $\mathbf{1 0}(60.0 \mathrm{~g}, 159 \mathrm{mmol})$, $\mathrm{N}$-bromosuccinimide $(30.3 \mathrm{~g}, 170 \mathrm{mmol})$, and a small amount of 2,2'-azobisisobutylnitrile was refluxed for $3 \mathrm{~h}$. After cooling, the solution was filtered and the solvent was removed to give pale yellow oil. The crude oil and anhydrous sodium acetate $(39.1 \mathrm{~g}$, $0.477 \mathrm{~mol})$ in acetic acid $(890 \mathrm{~mL})$ were refluxed at $130^{\circ} \mathrm{C}$ for $12 \mathrm{~h}$. After cooling, the solvent was removed, then the mixture was dissolved in dichloromethane, washed with water, and dried. The solution was evaporated, and aqueous sodium hydroxide $(4 \mathrm{~N}$, $180 \mathrm{~mL}$ ) was added, then the mixture was refluxed for $2 \mathrm{~h}$. The solvent was removed, dissolved in chloroform, and washed with water. The organic layer was then evaporated. The crude product was purified by column chromatography on silica gel with a chloroform eluent to give a white solid of $\mathbf{1 1}(30.6 \mathrm{~g})$. Yield 49\%. ${ }^{1} \mathrm{H} \mathrm{NMR}\left(\mathrm{CDCl}_{3}, 500 \mathrm{MHz} ; \mathrm{ppm}\right) \delta 7.68(\mathrm{~s}$, $1 \mathrm{H}), 7.06(\mathrm{~s}, 1 \mathrm{H}), 4.68(\mathrm{~d}, J=6.0 \mathrm{~Hz}, 2 \mathrm{H}), 4.03(\mathrm{t}$, $J=6.6 \mathrm{~Hz}, 2 \mathrm{H}), 2.00(\mathrm{t}, J=5.9 \mathrm{~Hz}, 1 \mathrm{H}), 1.86-1.80$ $(\mathrm{m}, 2 \mathrm{H}), 1.52-1.46(\mathrm{~m}, 2 \mathrm{H}), 1.39-1.26(\mathrm{~m}, 8 \mathrm{H})$, 0.89 (t, $J=7.0 \mathrm{~Hz}, 3 \mathrm{H}) ;{ }^{13} \mathrm{C} \mathrm{NMR}\left(\mathrm{CDCl}_{3}, 125\right.$ $\mathrm{MHz} ;$ ppm) $\delta 155.3,139.9,135.9,112.9,112.0$, 111.6, 69.6, 64.7, 31.8, 29.3, 29.2, 29.0, 26.0, 22.7, 14.1; MS (EI) m/e $392\left[(\mathrm{M}-2)^{+}\right], 394\left(\mathrm{M}^{+}\right), 396$ $\left[(\mathrm{M}+2)^{+}\right], 394.1$ (calcd); Anal. Calcd for $\mathrm{C}_{15} \mathrm{H}_{22}-$ $\mathrm{Br}_{2} \mathrm{O}_{2}: \mathrm{C}, 45.7 \% ; \mathrm{H}, 5.6 \% ; \mathrm{Br}, 40.6 \%$. Found: C, $45.6 \%$; $\mathrm{H}, 5.5 \%$; $\mathrm{Br}, 40.5 \%$.

\section{2,4-Dibromo-5-octyloxybenzaldehyde 12}

The compound $11(29.0 \mathrm{~g}, 73.6 \mathrm{mmol})$ and pyridinium chlorochromate $(23.8 \mathrm{~g}, 110 \mathrm{mmol})$ were dissolved in dichloromethane $(401 \mathrm{~mL})$, and the mixture was refluxed for $2 \mathrm{~h}$ at $40^{\circ} \mathrm{C}$. After cooling, the solution was filtered, and evaporated. The crude product was purified by silica gel column chromatography using dichloromethane as the eluent, then recrystallization from hexane gave a white needle crystal of $\mathbf{1 2}$ (26.2 g). mp. $64.5^{\circ} \mathrm{C}$. Yield 91\%. ${ }^{1} \mathrm{H}$ NMR $\left(\mathrm{CDCl}_{3}\right.$, $500 \mathrm{MHz}$; ppm) $\delta 10.2(\mathrm{~s}, 1 \mathrm{H}), 7.84(\mathrm{~s}, 1 \mathrm{H}), 7.38(\mathrm{~s}$, $1 \mathrm{H}), 4.07(\mathrm{t}, J=6.4 \mathrm{~Hz}, 2 \mathrm{H}), 1.87-1.82(\mathrm{~m}, 2 \mathrm{H})$, $1.52-1.46(\mathrm{~m}, 2 \mathrm{H}), 1.39-1.26(\mathrm{~m}, 8 \mathrm{H}), 0.89(\mathrm{t}, J=$ $7.0 \mathrm{~Hz}, 3 \mathrm{H}) ;{ }^{13} \mathrm{C} \mathrm{NMR}\left(\mathrm{CDCl}_{3}, 125 \mathrm{MHz} ; \mathrm{ppm}\right) \delta$ 
191.0, 155.6, 137.5, 133.0, 120.5, 117.5, 111.9, 69.7, $31.8,29.2,29.2,28.8,25.9,22.7,14.1$; MS (EI) $m / e$ $390\left[(\mathrm{M}-2)^{+}\right], 392\left(\mathrm{M}^{+}\right), 394\left[(\mathrm{M}+2)^{+}\right], 392.1$ (calcd); Anal. Calcd for $\mathrm{C}_{15} \mathrm{H}_{20} \mathrm{Br}_{2} \mathrm{O}_{2}: \mathrm{C}, 45.9 \% ; \mathrm{H}$, $5.1 \%$; Br, 40.8\%. Found: C, $45.7 \%$; H, 5.2\%; $\mathrm{Br}$, $40.6 \%$.

4-Bromo-2-[4-(N,N-bis(4-methoxyphenyl)amino)phenyl]-5-octyloxybenzaldehyde $\mathbf{1 3}$

To a DMF solution of $\mathbf{1 2}(2.00 \mathrm{~g}, 5.10 \mathrm{mmol})$, $4(2.20 \mathrm{~g}, 5.10 \mathrm{mmol})$, and potassium phosphate $(1.63 \mathrm{~g}, 7.68 \mathrm{mmol})$ was added tetrakis(triphenylphosphine)palladium $(0) \quad(0.110 \mathrm{mg}, 0.104 \mathrm{mmol})$ which was then reacted for $20 \mathrm{~h}$ at $100^{\circ} \mathrm{C}$. After removal of the solvent, the mixture was dissolved in dichloromethane, and the solution was washed with water, and dried over anhydrous sodium sulfate. The crude product was purified by flash column chromatography (hexane/dichloromethane $=11 / 2$ ) to afford an orange oil of $13(0.85 \mathrm{~g})$. Yield 27\%. ${ }^{1} \mathrm{H} \mathrm{NMR}\left(\mathrm{CDCl}_{3}\right.$, $500 \mathrm{MHz}$; ppm) $\delta 9.96(\mathrm{~s}, 1 \mathrm{H}), 7.66(\mathrm{~s}, 1 \mathrm{H}), 7.44$ (s, $1 \mathrm{H}), 7.12-7.09(\mathrm{~m}, 6 \mathrm{H}), 6.95(\mathrm{~d}, J=8.8 \mathrm{~Hz}, 2 \mathrm{H})$, $6.86(\mathrm{~d}, J=8.8 \mathrm{~Hz}, 4 \mathrm{H}), 4.11(\mathrm{t}, J=6.5 \mathrm{~Hz}, 2 \mathrm{H})$, $3.81(\mathrm{~s}, 6 \mathrm{H}), 1.89-1.85(\mathrm{~m}, 2 \mathrm{H}), 1.51-1.50(\mathrm{~m}, 2 \mathrm{H})$, $1.30-1.26(\mathrm{~m}, 8 \mathrm{H}), 0.89-0.88(\mathrm{~m}, 3 \mathrm{H}) ;{ }^{13} \mathrm{C} \mathrm{NMR}$ $\left(\mathrm{CDCl}_{3}, 125 \mathrm{MHz}\right.$; ppm) $\delta 192.0,156.3,154.8,149.0$, $140.4,139.7,135.4,133.4,130.8,127.3,127.0,119.4$, $119.1,114.9,110.0,69.6,55.5,31.8,29.3,29.2,29.0$, 26.0, 22.7, 14.1; MS (EI) $m / e 615\left[(\mathrm{M}-1)^{+}\right], 617$ $\left[(\mathrm{M}+1)^{+}\right], 616.6$ (calcd); Anal. Calcd for $\mathrm{C}_{35} \mathrm{H}_{38^{-}}$ $\mathrm{BrNO}_{4}$ : C, 68.2\%; H, 6.2\%; $\mathrm{Br}, 13.0 \% ; \mathrm{N}, 2.3 \%$. Found: C, $68.1 \%$; H, $6.0 \%$; Br, $13.1 \%$; N, $2.1 \%$.

4-Bromo-2-[4-(N,N-bis(4-methoxyphenyl)amino)phenyl]-5-octyloxystyrene 14

A $1.57 \mathrm{M}$ hexane solution of $n$-butyllithium $(1.7$ $\mathrm{mL}, 2.67 \mathrm{mmol}$ ) was dropwise added to a dry THF solution of methyltriphenylphosphonium bromide $(1.40 \mathrm{~g}, 3.91 \mathrm{mmol})$ at $-20^{\circ} \mathrm{C}$ under nitrogen and stirred for $1 \mathrm{~h}$. To the solution was then added a solution of $13(0.853 \mathrm{~g}, 1.38 \mathrm{mmol})$ in dry THF $(8.9 \mathrm{~mL})$ at $-20^{\circ} \mathrm{C}$. After the solution was stirred for $1 \mathrm{~h}$, the mixture was allowed to warm to room temperature and was reacted for $12 \mathrm{~h}$. To the reaction mixture were added ether and water. The organic layer was extracted and dried. After removal of the solvent, the crude product was purified by flash column chromatography (hexane/ethyl acetate $=20 / 1$ ) to afford a pale yellow solid of $14(0.338 \mathrm{~g})$. Yield $40 \%$. ${ }^{1} \mathrm{H}$ NMR $\left(\mathrm{CDCl}_{3}\right.$, $500 \mathrm{MHz} ; \mathrm{ppm}) \delta 7.47(\mathrm{~s}, 1 \mathrm{H}), 7.10-7.07(\mathrm{~m}, 7 \mathrm{H})$, $6.92(\mathrm{~d}, J=8.7 \mathrm{~Hz}, 2 \mathrm{H}), 6.84(\mathrm{~d}, J=9.0 \mathrm{~Hz}, 4 \mathrm{H})$, $6.74(\mathrm{dd}, J=17.5,11.0 \mathrm{~Hz}, 1 \mathrm{H}), 5.66(\mathrm{dd}, J=$ $17.4,0.9 \mathrm{~Hz}, 1 \mathrm{H}), 5.21(\mathrm{dd}, J=11.0,0.9 \mathrm{~Hz}, 1 \mathrm{H})$. $4.08(\mathrm{t}, J=6.5 \mathrm{~Hz}, 2 \mathrm{H}), 3.80(\mathrm{~s}, 6 \mathrm{H}), 1.89-1.83(\mathrm{~m}$, $2 \mathrm{H}), 1.55-1.49(\mathrm{~m}, 2 \mathrm{H}), 1.41-1.30(\mathrm{~m}, 8 \mathrm{H}), 0.89(\mathrm{t}$,
$J=6.9 \mathrm{~Hz}, 3 \mathrm{H}) ;{ }^{13} \mathrm{C} \mathrm{NMR}\left(\mathrm{CDCl}_{3}, 125 \mathrm{MHz} ; \mathrm{ppm}\right)$ $\delta 155.9,154.4,147.8,140.9,135.9,135.8,134.6$, $134.4,131.0,130.3,126.7,119.7,114.7,114.5$, $111.7,110.0,69.4,55.5,31.8,29.3,29.2,29.1,26.0$, 22.7, 14.1; MS (EI) $m / e \quad 613\left[(\mathrm{M}-1)^{+}\right], \quad 615$ $\left[(\mathrm{M}+1)^{+}\right], 614.6$ (calcd); Anal. Calcd for $\mathrm{C}_{36} \mathrm{H}_{40^{-}}$ $\mathrm{BrNO}_{3}: \mathrm{C}, 70.3 \% ; \mathrm{H}, 6.6 \% ; \mathrm{Br}, 13.0 \% ; \mathrm{N}, 2.3 \%$. Found: C, $70.0 \%$; H, $6.4 \%$; Br, $12.8 \%$; N, $2.1 \%$.

\section{Materials}

$\mathrm{N}$-(4-Bromophenyl)- $\mathrm{N}, \mathrm{N}$-bis(4-dimethoxyphenyl)amine $\mathbf{3},{ }^{21 \mathrm{a}} 2,3^{\prime}$-dibromostilbene $\mathbf{5},{ }^{22}$ and 2 -bromo5-(2-ethylhexyloxy)terephthalaldehyde $\mathbf{6}^{16}$ were prepared according to the literature. 2,4-Dibromo-5octyloxytoluene $\mathbf{1 0}$ was prepared via the Williamson reaction of 4,6-dibromo-1,3-cresol. ${ }^{23}$ All other reagents were commercially available and used without further purification.

\section{Gilch Polymerization}

To a solution of $9(0.870 \mathrm{~g}, 1.43 \mathrm{mmol})$ and $t$-butylbenzylchloride $(0.30 \mathrm{~mL}, 1.77 \mathrm{mmol})$ in THF $(19.5$ $\mathrm{mL}, \quad 0.073 \mathrm{M}$ ) was added potassium $t$-butoxide $(0.902 \mathrm{~g}, 8.04 \mathrm{mmol})$ at $0{ }^{\circ} \mathrm{C}$ and then the mixture was stirred for $5 \mathrm{~min}$ at $60^{\circ} \mathrm{C}$. The reaction mixture was poured into methanol, and the precipitate was washed with methanol and dissolved in THF. The THF solution was reprecipitated in methanol and the precipitate was then washed with methanol to yield a pale orange powder of $1(0.217 \mathrm{~g})$. Yield $25 \%$. ${ }^{1} \mathrm{H}$ NMR $\left(\mathrm{CDCl}_{3}, 600 \mathrm{MHz} ; \mathrm{ppm}\right) \delta$ 6.94-6.74 (br $16 \mathrm{H}), 3.72$ (br $8 \mathrm{H}), 1.26$ (br 9H), 0.84 (br, 6H). Anal. Calcd for $\mathrm{C}_{36} \mathrm{H}_{39} \mathrm{NO}_{3}$ : C, $81.0 \%$; $\mathrm{H}, 7.4 \%$;, $2.6 \%$. Found: C, $80.8 \%$; H, $7.5 \%$; N, 2.8\%; Cl; $0.32 \%$.

\section{Heck Polymerization}

A solution of palladium(II) acetate $(18.4 \mathrm{mg}, 82.0$ $\mu \mathrm{mol})$, tri-o-tolylphosphine $(80.0 \mathrm{mg}, 263 \mu \mathrm{mol})$, triethylamine $(334 \mathrm{mg}, 3.30 \mu \mathrm{mol})$, and $14(1.01 \mathrm{~g}$, $1.64 \mu \mathrm{mol})$ in DMF $(16.4 \mathrm{~mL}, 0.1 \mathrm{M}$ of $\mathbf{1 4})$ was stirred at $100{ }^{\circ} \mathrm{C}$ for $60 \mathrm{~h}$. The solution was poured into methanol and the precipitate was purified by reprecipitating from THF into methanol to yield a yellow powder of $15(0.564 \mathrm{~g}) .{ }^{1} \mathrm{H} \mathrm{NMR}\left(\mathrm{CDCl}_{3}, 500 \mathrm{MHz} ; \mathrm{ppm}\right) \delta$ 7.46-5.82 (br 48H), 3.73-3.62 (br 24H), 2.02-0.84 (br, 45H). FAB-MS $m / z 1682$ (trimer calc. 1682.0). Anal. Calcd for $\mathrm{C}_{108} \mathrm{H}_{118} \mathrm{BrN}_{3} \mathrm{O}_{9} \quad(\mathrm{DP}=3)$ : $\mathrm{C}$, $77.1 \% ; \mathrm{H}, 7.1 \% ; \mathrm{Br}, 4.8 \% ; \mathrm{N}, 2.5 \%$. Found: $\mathrm{C}$, $76.9 \% ; \mathrm{H}, 7.0 \% ; \mathrm{Br}, 4.9 \% ; \mathrm{N}, 2.4 \%$.

\section{Oxidation}

To a dichloromethane $(9.4 \mathrm{~mL})$ solution of the triarylamine-bearing polymer $\mathbf{1}(50 \mathrm{mg})$ were added $1.9 \mathrm{~mL}$ of trifluoroacetic acid (TFA), $7.5 \mathrm{~mL}$ of trifluoroacetic anhydride (TFAA), and nitrosonium 

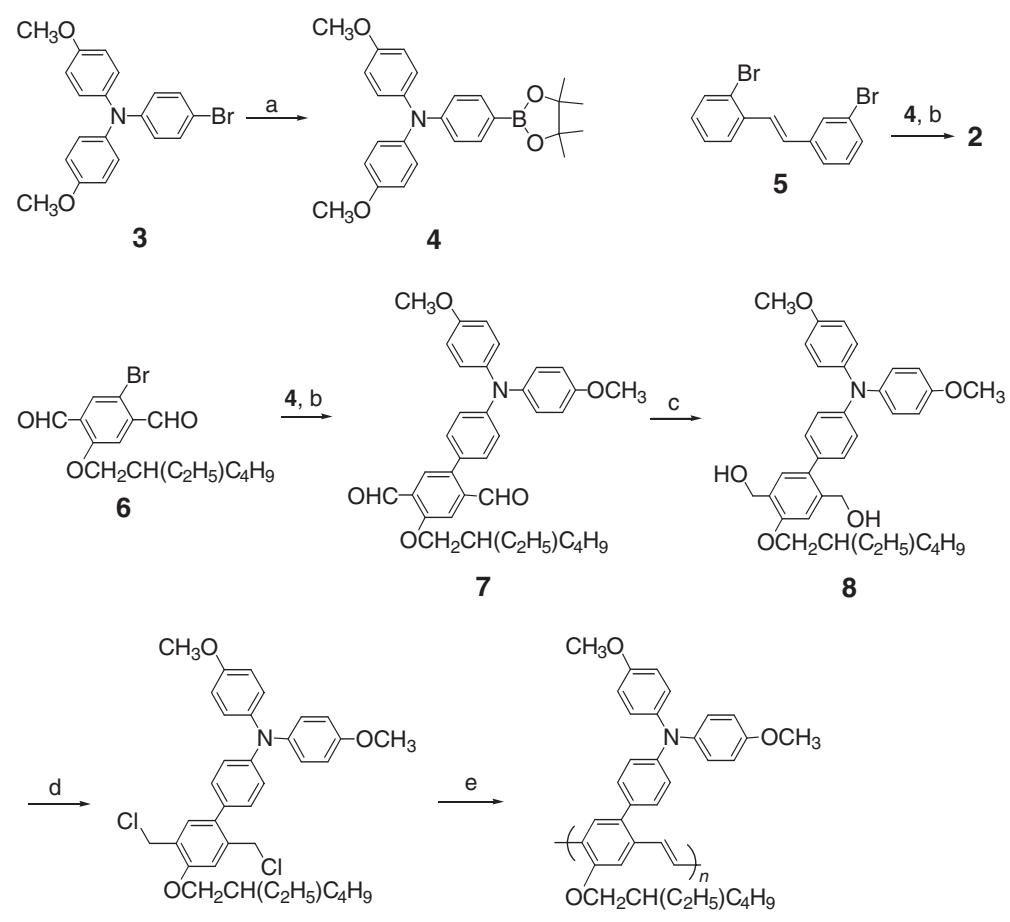

9

1

Scheme 1. Preparation route for the polymer 1 and the dimer 2. (a) (1) $n$-butyllithium, THF, $-78^{\circ} \mathrm{C}$; (2) triisopropylborate, THF; (3) pinacol, THF; (b) tetrakis(triphenylphosphine)palladium(0), potassium phosphate, DMF; (c) lithium aluminum hydride, THF; (d) triphenylphosphine, tetrachloromethane; (e) potassium- $t$-butoxide, THF.

hexafluorophosphate $\left(\mathrm{NOPF}_{6}, 18.0 \mathrm{mg}, 0.103 \mathrm{mmol}\right)$. The solution was stirred at room temperature for $15 \mathrm{~min}$, and the solvent was evaporated to afford a powder of the polyradical $\mathbf{1}^{+}$. The stilbene derivative $2(9.40 \mathrm{mg}, 12.0 \mu \mathrm{mol})$ was also oxidized in $\mathrm{CH}_{2} \mathrm{Cl}_{2} /$ TFA/TFAA $(0.1 \mathrm{~mL} / 0.03 \mathrm{~mL} / 0.12 \mathrm{~mL})$ with $\mathrm{NOPF}_{6}$ $(5.3 \mathrm{mg}, 30 \mu \mathrm{mol})$ in the presence of 18 -crown-6 (4.1 $\mathrm{mg}, 16 \mu \mathrm{mol})$ to yield a dark green solution of $\mathbf{2}^{+}$.

\section{Measurements}

The ${ }^{1} \mathrm{H}$ and ${ }^{13} \mathrm{C}$ NMR spectra were recorded using a JEOL-Lambda 500 or Bruker AVANCE-600 spectrometer. The Mass and FAB-Mass spectra were obtained using a Shimadzu GC-MS 17A and a JEOL JMS-SX102A spectrometer, respectively. The UV-vis spectra were measured by a JASCO V-550 spectrometer. The fluorescence spectra were obtained using a Hitachi F-4500 spectrometer. The gel permeation chromatography was performed by a Tosoh LS-8000 (TKL-GEL GMHXL column $(\phi=7.8 \mathrm{~mm}, \mathrm{~L}=300$ $\mathrm{mm})$ analyzer with a THF eluent and polystyrene standards. The thermal analyses were performed by SEIKO DSC 220C and TG/DTA220 thermal analyzers at the heating rate of $10^{\circ} \mathrm{C} / \mathrm{min}$ under nitrogen.

The electrochemical measurements were carried out using a BAS 100B/W electrochemical analyzer (Bioanalytical Systems, Inc., Japan). The working, the counter, and the reference electrodes were a plat- inum disk, a platinum wire, and a saturated $\mathrm{Ag} / \mathrm{AgCl}$, respectively. All cyclic voltammograms were rescaled to the formal redox potential of the ferrocene/ferrocenium couple.

The ESR spectra were recorded by a JEOL LESTE200 ESR spectrometer with $100-\mathrm{kHz}$ field modulation. The temperature dependence plots of the ESR signal intensities were measured by a 9650 digital temperature controller (Scientific Instruments, Inc., USA). The magnetizations were measured by a Quantum Design MPMS-7 SQUID magnetometer.

\section{RESULTS AND DISCUSSION}

The monomer for the Gilch polycondensation, 1,4bis(chloromethyl)-2-[4-( $N, N$-bis(4-methoxyphenyl)amino)phenyl]-5-(2-ethylhexyloxy)benzene 9, was prepared as shown in Scheme 1. N,N-Bis(4-methoxytphenyl)-4-bromophenylamine $\mathbf{3}$ was prepared by the bromination of $4,4^{\prime}$-dimethoxytriphenylamine with $\mathrm{N}$-bromosuccinimide in chloroform. The lithiated bromotriphenylamine 3 was reacted with tri(i-propyl)borate and pinacol to produce the derivative of triarylamine pinacol boronate 4. 2-Bromo-5-(2-ethylhexyloxy)terephthalaldehyde $\mathbf{6}$ was coupled with the pinacol boronate 4 in the presence of a palladiumphosphine catalyst to yield the triphenylamine-bearing terephthalaldehyde $\mathbf{7}$. The treatment of $\mathbf{7}$ with lithium 

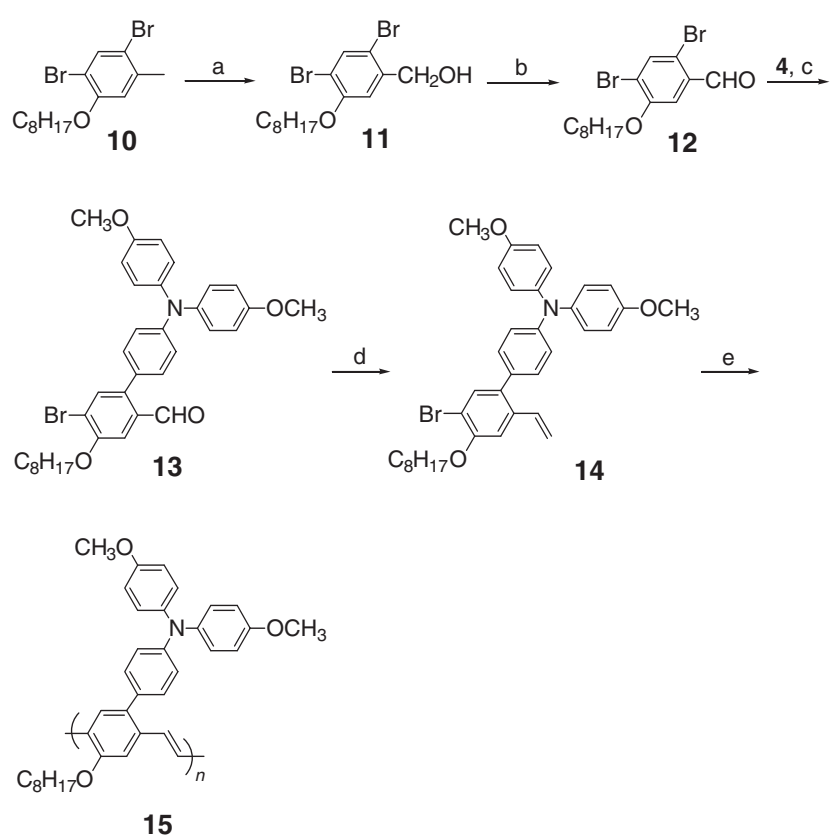

Scheme 2. Preparation route for the polymer 15. (a) (1) $N$-bromosuccinimide, $\alpha, \alpha^{\prime}$-azobisisobutylonitrile, tetrachloromethane; (2) acetic anhydride, sodium acetate; (3) sodium hydroxide, methanol; (b) pyridinium chlorochromate, dichloromethane; (c) tetrakis(triphenylphosphine)palladium(0), potassium phosphate, DMF; (d) (1) n-butyllithium, methyltriphenylphosphonium bromide, THF; (e) palladium(II) acetate, tri(o-tolyl)phosphine, triethylamine, DMF.

aluminium hydride provided the diol derivative $\mathbf{8}$, which was chlorinated with triphenylphosphine and tetrachloromethane to give the bis(choloromethyl)benzene derivative 9 as the monomer for the Gilch reaction.

2,3'-Dibromostilbene 5 was coupled with the pinacol boronate derivative of triarylamine 4 via the Suzuki coupling reaction to afford the triarylaminebearing stilbene $\mathbf{2}, 2,3^{\prime}$-bis[4- $\{N, N$-bis(4-methoxyphenyl)amino\}phenyl]stilbene, as the dimer model compound.

The triarylamine-bearing bromostyrene derivative 14 was also prepared in 4 steps from 2,4-dibromo5-octyloxytoluene $\mathbf{1 0}$ which was obtained by the Williamson reaction of 4,6-dibromo-1,3-cresol. ${ }^{23}$

The Gilch polycondensation of the monomer 9 in the presence of 4-t-butylbenzylchloride afforded the polymer 1 (Table I). The addition of 4-t-butylbenzylchloride ${ }^{24}$ before the reaction suppressed the insoluble gel formation (entry 2). The number-average molecular weight $\left(M_{\mathrm{n}}\right)$ of 1 was $4.0 \times 10^{5} \mathrm{~g} / \mathrm{mol}$ or the degree of polymerization of 750 . The polymer 1 was soluble in common solvents such as chloroform, THF, and DMF. The ${ }^{1} \mathrm{H}$ NMR spectrum of 1 revealed that the content of the residual ethylene chloride or aliphatic defect in the backbone was $c a .4 .8 \%$ estimated by the signal peak at $5.2 \mathrm{ppm}$ (Figure 1). Though the regioregularity of the polymer $\mathbf{1}$ was not clarified using the NMR spectrum, the bulky substituents are expected to form the highly-regioregular polyphenylenevinylene backbone. The chlorine content estimated from the elemental analysis was $0.3 \%$, indicating the high chemical purity ( $>99.5 \%$ ) of $\mathbf{1}$. This high purity was comparable to that of the previously-reported poly(2-methoxy-5-(2'-ethylhexyloxy)-1,4-phenylenevinylene) via the Gilch polycondensation (chloride content $<0.5 \%{ }^{24}$ ).

The Heck reaction of the 4-bromostyrene monomer 14 was carried out as the control polymerization. The palladium-catalyzed Heck reaction of $\mathbf{1 4}$ yielded only the low molecular weight oligomer (degree of polymerization $=3$ ) (Table I) while the structure of the oligomer was definitely assigned to the head-to-tail linked trimer, tris[2-\{N,N-bis(4-methoxyphenyl)amino $\}$ phenyl-5-octyloxy-1,4-phenylenevinylene], based on the NMR and FAB-MS spectra (see Experimental). Taking into account the results from the FAB-MS and elemental analysis, the end groups, i.e., the bromide and vinyl moieties, were still substituted in the trimer, indicating that the bulky triarylamine substituent significantly reduced the reactivity of the monomer. These results concluded that the Gilch polycondensation was appropriate for producing the high molecular weight polymer of $\mathbf{1}$ with the chemical structure as represented in Scheme 1.

The thermal stability and glass transition temperature of $\mathbf{1}$ were examined by thermogravimetric analysis and differential scanning calorimetric analysis, respectively. The 10\%-weight-loss temperature under nitrogen atmosphere was $440{ }^{\circ} \mathrm{C}$ and no weight-loss of the polymer was observed up to $350^{\circ} \mathrm{C}$. The glass transition temperature was $163^{\circ} \mathrm{C}$ without any evi-

Table I. Polymerization of $\mathbf{9}$ and $\mathbf{1 4}$ via the Gilch and Heck reaction, respectively

\begin{tabular}{cccccccc}
\hline Entry & monomer & $\begin{array}{c}{[\mathrm{M}]_{0}} \\
(\mathrm{~mol} / \mathrm{L})\end{array}$ & $\begin{array}{c}\text { Additive }^{a} \\
(\mathrm{~mol} / \mathrm{L})\end{array}$ & Time & $\begin{array}{c}\text { Yield }^{b} \\
(\%)\end{array}$ & $M_{\mathrm{n}}\left(10^{3}\right)$ & $M_{\mathrm{w}} / M_{\mathrm{n}}$ \\
\hline 1 & \multirow{2}{*}{} & 0.08 & - & $5 \mathrm{~min}$ & 7.5 & 590 & 1.6 \\
2 & & 0.08 & 0.09 & $5 \mathrm{~min}$ & 65 & 400 & 2.2 \\
3 & \multirow{2}{14}{} & 0.1 & - & $24 \mathrm{~h}$ & 28 & 1.6 & 1.3 \\
4 & 0.1 & - & $60 \mathrm{~h}$ & 56 & 1.5 & 1.2 \\
\hline
\end{tabular}

$a$ : 4-( $t$-Butyl)benzylchloride, $b$ : THF-soluble part. 


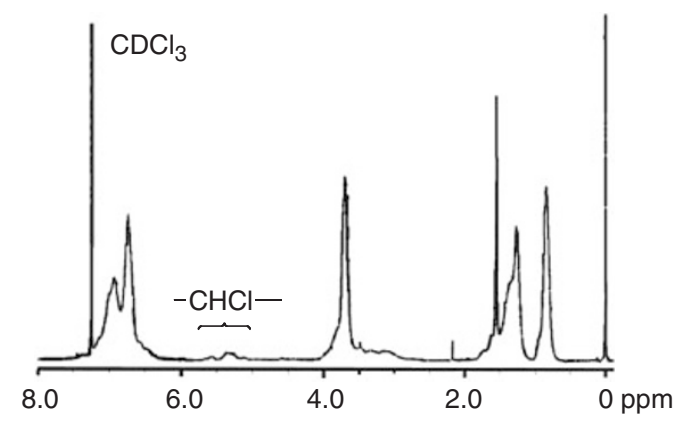

Figure 1. ${ }^{1} \mathrm{H}$ NMR spectrum of the polymer 1 obtained via the Gilch polycondensation of the monomer 9.

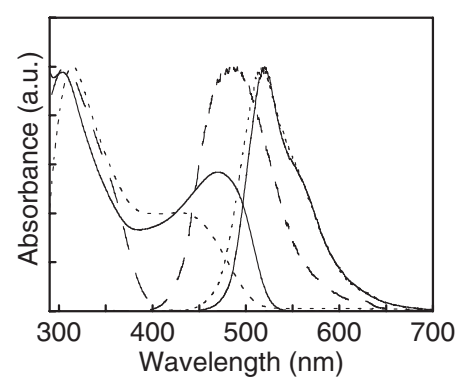

Figure 2. UV-vis absorption and photoluminescence spectra of the polymer 1 (solid line), the dimer model $\mathbf{2}$ (dashed line), and the polymer $\mathbf{1 5}$ (dotted line) in the $\mathrm{CHCl}_{3}$ solution.

dence of crystallinity. These thermal properties supported the high thermal stability and homogeneous film formability of the polymer 1 .

The UV-vis absorption and photoluminescent (PL) spectra of the polymer $\mathbf{1}$, the dimer model $\mathbf{2}$, and the oligomer obtained via the Heck reaction $\mathbf{1 5}$ in chloroform solutions are shown in Figure 3. The dimer model 2 showed an absorption maximum at $308 \mathrm{~nm}$ with a shoulder near $360 \mathrm{~nm}$. The former is attributed to the $n-\pi^{*}$ transition derived from the triarylamine moiety and the latter is assigned to the $\pi-\pi^{*}$ absorption band of the stilbene structure. 2 exhibited a yellowish-green emission with the luminescent maximum at $490 \mathrm{~nm}$ ascribed to the stilbene chromophore. The polymer 1 showed two absorption peaks at 300 and $470 \mathrm{~nm}$ assigned to the triarylamine moiety and the phenylenevinylene backbone, respectively. The chloroform solution of $\mathbf{1}$ emitted a strong yellow luminescence with the maximum at $527 \mathrm{~nm}$ derived from the poly(1,4-phenylenevinylene) backbone, which was red-shifted in comparison with that of 2 . The bathochromic shift of the UV absorption spectrum and the red shift of PL spectrum for $\mathbf{1}$ when compared to those for $\mathbf{2}$ indicated that the polymer obtained by the Gilch polycondensation possesses an extended $\pi$-conjugation structure of poly $(1,4$-phenylenevinylene). This was also supported by the result that $\mathbf{1 5}$ via the Heck reaction showed a $\pi-\pi^{*}$ absorption band
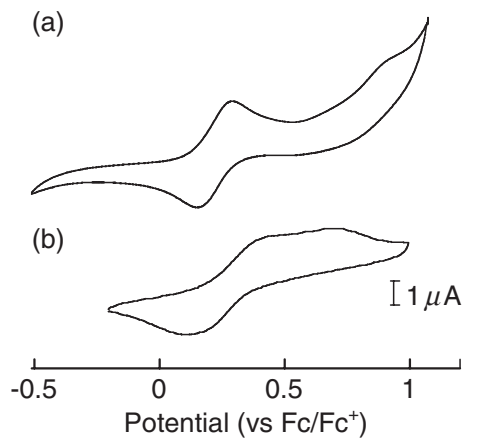

Figure 3. Cyclic voltammograms of (a) $\mathbf{1}$ and (b) $\mathbf{2}$ in a $\mathrm{CH}_{2} \mathrm{Cl}_{2}$ solution with $0.1 \mathrm{M}\left(\mathrm{C}_{4} \mathrm{H}_{9}\right)_{4} \mathrm{NBF}_{4}$. scan rate $=100 \mathrm{mV} / \mathrm{s}$.

at $440 \mathrm{~nm}$. The optical energy-level gap between the highest occupied molecular orbital (HOMO) and the lowest molecular orbital (LUMO) was estimated to be $2.30,3.02$, and $2.43 \mathrm{eV}$ for $\mathbf{1}, \mathbf{2}$, and $\mathbf{1 5}$, respectively, which corresponded to the extension of the $\pi$-conjugation in $\mathbf{1}$. It is considered that the low aliphatic defect content in the backbone of $\mathbf{1}$ was not crucial for the $\pi$-conjugation of poly(1,4-phenylenevinylene). The film of $\mathbf{1}$ also displayed a strong yellowish emission under UV irradiation, suggesting that polymer $\mathbf{1}$ is applicable as an emitting layer in OLED devices.

Cyclic voltammograms of the polymer $\mathbf{1}$ and the dimer model $\mathbf{2}$ in the dichloromethane solution are shown in Figure 3. The redox potentials $\left(E_{1 / 2}=\right.$ $\left.\left(E_{\mathrm{p}}{ }^{\mathrm{a}}+E_{\mathrm{p}}{ }^{\mathrm{c}}\right) / 2\right)$ of 1 and 2 were 0.22 and $0.27 \mathrm{~V}$, respectively. The redox potentials of $\mathbf{1}$ and $\mathbf{2}$ were comparable to that of tris(4-methoxyphenyl)amine $\left(E_{1 / 2}=\right.$ $\left.0.12 \mathrm{~V}^{11 \mathrm{~b}}\right)$. The unimodal redox waves suggested that the pendant triarylamine group was electrochemically oxidized almost in one step, corresponding to the electrochemical formation ${ }^{25}$ of a triarylaminium cation radical. The dichloromethane solution of $\mathbf{1}$ turned deep-blue upon electrochemical oxidation, which was supported by the strong ESR signal appearance during electrolysis at $0.5 \mathrm{~V}$. The slightly lower oxidation potential of $\mathbf{1}$ than that of $\mathbf{2}$ could be ascribed to the electron-donating effect of the ethylhexyloxy group attached to the phenylene unit. The reversible redox waves suggested no competing subsequent side-reactions such as dimerization or disproprtionation of the triarylaminium radical formed on the pendant moiety of the polymer during the electrochemical oxidation in the solution.

The polymer 1 and the dimer model 2 were reacted with the nitrosonium hexafluorophosphate ${ }^{26}$ as an oxidizing agent in the dichloromethane solutions in the presence of a small amount of trifluoroacetic acid $(\mathrm{TFA})^{27}$ and trifluoroacetic anhydride (TFAA). The solution of $\mathbf{1}$ or $\mathbf{2}$ turned deep-blue through the chemical oxidation, and the ESR spectra $\left(\Delta M_{\mathrm{s}}= \pm 1\right)$ of the 

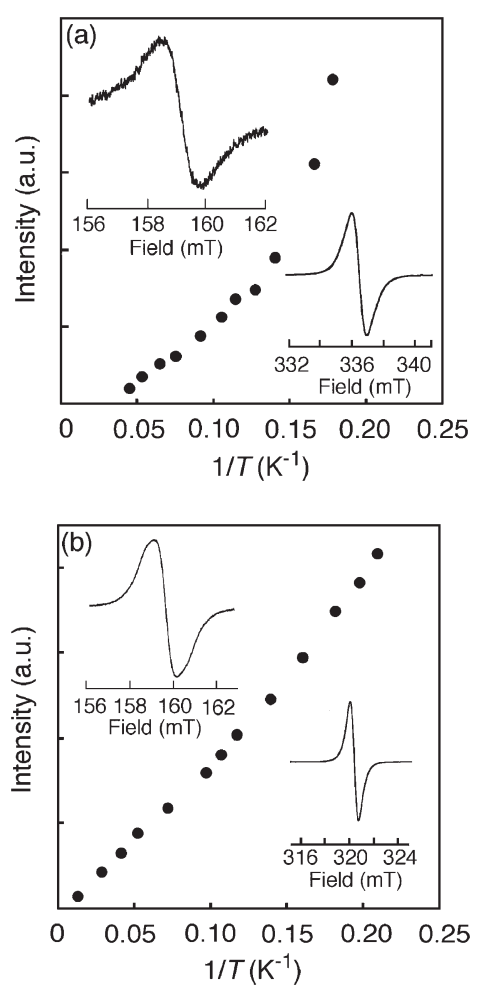

Figure 4. Curie plots for the peak in the $\Delta M_{\mathrm{s}}= \pm 2$ region for (a) the polyradical $\mathbf{1}^{+}$and (b) the diradical $\mathbf{2}^{+}$. Inset: ESR spectra in the $\Delta M_{\mathrm{s}}= \pm 2$ region at $4.8 \mathrm{~K}$ and ESR spectra in $\Delta M_{\mathrm{s}}= \pm 1$ region at room temperature.

formed solution at room temperature showed a strong unimodal signal at $g=2.0046$ and 2.0031, respectively. The spin concentration estimated from the ESR signal intensities was 0.34 for $\mathbf{1}^{+}$spin/unit and 0.94 for $\mathbf{2}^{+}$. It is considered that the irregular head-to-head or tail-to-tail linkage in the poly(1,4-phenylenevinylene) structure of $\mathbf{1}^{+}$partially sacrificed the nonKekulé connection, leading to the low spin concentration of $\mathbf{1}^{+}$.

The ESR study at cryogenic temperature for the polyradical $\mathbf{1}$ and the diradical $\mathbf{2}^{+}$is shown in Figure 4. The ESR spectrum had an absorption in the $g=4$ region, ascribed to the forbidden transition $\left(\Delta M_{\mathrm{s}}= \pm 2\right)$ or to a triplet state formation at low temperature. The $\Delta M_{\mathrm{s}}= \pm 2$ signal intensity $v s$. the reciprocal temperature plots (the Curie plots) produced a steep upward deviation below $7 \mathrm{~K}$ for the polyradical $\mathbf{1}^{+}$, while those of the diradical $\mathbf{2}^{+}$showed a linear Curie-type relationship (Figure 4). These results indicated that the polyradical $\mathbf{1}^{+}$is in a ground state triplet or a multiplet state with an appropriate triplet(multiplet)-singlet energy gap, and that the diradical $\mathbf{2}^{+}$is in a degenerated state of the singlet and triplet. Based on these results, the phenylenevinylene backbone was effective for the intramolecular through-bond ferromagnetic interaction among the pendant spins or a spin-alignment for the polyradical $\mathbf{1}^{+}$.

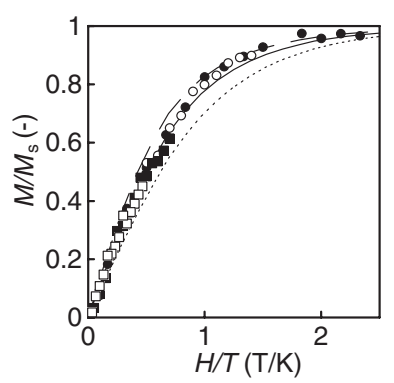

Figure 5. Normalized plots of magnetization $\left(M / M_{\mathrm{s}}\right)$ vs. the ratio of magnetic field and temperature $(H / T)$ for the polyradical $\mathbf{1}^{+}$at 3.0 (closed circle), 5.0 (open circle), 10 (closed square), 15 (open square) $\mathrm{K}$ and theoretical Brillouin curves of $S=2 / 2$ (dotted line), 3/2 (solid line), and 4/2 (dashed line).

The normalized plots of magnetization $\left(M / M_{\mathrm{s}}\right)$ of the polyradical $\mathbf{1}^{+}$using a SQUID magnetometer is shown in Figure 5. The sample was diluted with tetrabutylammonium poly(styrenesulfonate) in a $1 / 100$ (wt/wt) ratio to suppress the intermolecular (throughspace) antiferromagnetic interaction. The $M / M_{\mathrm{s}}$ plots (Weiss temperature $=0 \mathrm{~K}$ ) were close to the theoretical Brillouin curve for $S=3 / 2$, indicating that the polyradical $\mathbf{1}^{+}$with the spin concentration of 0.29 is a quartet polymer. The results from this study concluded that the poly(phenylenevinylene) backbone formed via the Gilch polycondensation included a small amount of the aliphatic bond and head-to-head linkage as the defects but this backbone is still effective to ferromagnetically interact between the pendant unpaired electron spins. The Gilch polycondensation is a promising method to prepare a high-spin polymer with a high-molecular weight and a film-formability applicable for device fabrication.

Acknowledgment. This work was partially supported by a Grant-in-Aid for Scientific Research on the Priority Area "Super-Hierarchiral Structures" from MEXT Japan. T.K. acknowledges the Research Fellowship of the Japan Society for the Promotion of Science for Young Scientists.

\section{REFERENCES}

1. a) "Magnetic Properties of Organic Materials," P. M. Lahti, Ed., Marcel Dekker, New York, 1999.

b) "Molecular Magnetism: New Magnetic Materials," K. Itoh and M. Kinoshita, Ed., Kohdansha and Gordon \& Breach, Tokyo and Amsterdam, 2000.

c) "Carbon-based Magnetism," T. Makarova and F. Palacio, Ed., Elsevier, Amsterdam, 2006.

2. a) H. Iwamura and N. Koga, Acc. Chem. Res., 26, 346 (1993).

b) A. Rajca, Chem. Rev., 94, 871 (1994).

c) H. Nishide, Adv. Mater., 7, 937 (1995).

d) A. Rajca, Chem. Eur. J., 8, 4834 (2002). 
3. W. T. Borden and E. R. Davidson, J. Am. Chem. Soc., 99, 4587 (1977).

4. A. Rajca, J. Wongsriratanakul, and S. Rajca, Science, 294, 1503 (2001).

5. E. Fukuzaki and H. Nishide, J. Am. Chem. Soc., 128, 996 (2006).

6. a) T. Michinobu, M. Takahashi, E. Tsuchida, and H. Nishide, Chem. Mater., 11, 1969 (1999).

b) E. Fukuzaki, N. Takahashi, S. Imai, H. Nishide, and A. Rajca, Polym. J., 37, 284 (2005).

7. a) H. Oka, T. Tamura, Y. Miura, and Y. Teki, J. Mater. Chem., 11, 1364 (2001).

b) Y. Miura, H. Oka, M. Morita, Macromolecules, 31, 2041 (1998).

8. a) H. Nishide, T. Kaneko, T. Nii, K. Katoh, E. Tsuchida, and K. Yamaguchi, J. Am. Chem. Soc., 117, 548 (1995).

b) H. Nishide, T. Kaneko, T. Nii, K. Katoh, E. Tsuchida, and P. M. Lahti, J. Am. Chem. Soc., 118, 9695 (1996).

c) M. Takahashi, Y. Nasu, and H. Nishide, Polym. J., 31, 203 (1999).

9. H. Nishide, T. Kaneko, S. Toriu, Y. Kuzumaki, and E. Tsuchida, Bull. Chem. Soc. Jpn., 69, 449 (1996).

10. H. Nishide, Y. Hozumi, T. Nii, and E. Tsuchida, Macromolecules, 30, 3986 (1997).

11. a) M. Takahashi, T. Nakazawa, E. Tsuchida, and H. Nishide, Macromolecules, 32, 6383 (1999).

b) H. Murata, T. Masahiro, K. Namba, N. Takahashi, and H. Nishide, J. Org. Chem., 69, 631 (2004).

c) H. Murata, D. Miyajima, and H. Nishide, Macromolecules, 39, 6331 (2006).

12. "Handbook of Organic Conductive Molecules and Polymers,” D. H. S. Nalwa, Ed., Wiley, New York, 1996.

13. a) J. H. Burroughes, D. D. C. Bradley, A. R. Brown, R. N. Marks, K. Machkey, R. H. Friend, P. L. Burn, and A. B. Holmes, Nature, 347, 539 (1990).

b) A. Kraft, A. C. Grimsdale, and A. B. Holmes, Angew. Chem., Int. Ed., 37, 402 (1998).

14. C. Brabec, V. Dyakonov, J. Parisi, and N. S. Sacriciftchi, "Organic Photovoltaics," Springer, Berlin, 2003.
15. E. K. Miller, K. Lee, K. Hasharoni, J. C. Hummelen, F. Wudl, and A. J. Heeger, J. Chem. Phys., 108, 1390 (1998).

16. Y.-J. Pu, T. Kurata, M. Soma, J. Kido, and H. Nishide, Synth. Met., 143, 207 (2004).

17. a) R. F. Heck, Org. React., 27, 345 (1982).

b) H. Weitzel and K. Müllen, Makromol. Chem., 191, 2837 (1990).

c) Z. Bao, Y. Chen, R. Cai, and L. Yu, Macromolecules, 26, 5281 (1993).

18. a) Z. Yang, I. Sokolik, and F. E. Karasz, Macromolecules, 26, 1188 (1993).

b) T. Ahn, S.-Y. Song, and H.-K. Shim, Macromolecules, 33, 6764, (2000).

19. a) H. G. Gilch and W. L. Wheelwright, J. Polym. Sci., Part A: Polym. Chem., 4, 1337 (1966).

b) J. A. Mikroyannidis, Chem. Mater., 15, 1865 (2003).

20. R. J. Bushby, D. R. McGill, K. M. Ng, and N. Taylor, J. Chem. Soc., Perkin Trans. 2, 1997, 1405.

21. a) Y.-J. Pu, M. Soma, J. Kido, and H. Nishide, Chem. Mater., 13, 3817 (2001).

b) M. Nomura, Y. Shibasaki, M. Ueda, K. Tugita, M. Ichikawa, and Y. Taniguchi, Macromolecules, 37, 1204 (2004).

22. P. J. van Meurs and R. A. J. Janssen, J. Org. Chem., 65, 5712 (2000).

23. R. C. Huston and J. A. Hutchinson, J. Am. Chem. Soc., 54, 1504 (1932).

24. a) B. R. Hsieh, Y. Yu, A. C. VanLeaken, and H. Lee, Macromolecules, 30, 8094 (1997).

b) B. R. Hsieh, Y. Yu, E. W. Forsythe, G. M. Schaaf, and W. A. Feld, J. Am. Chem. Soc., 120, 231 (1998).

25. J. S. Cho, K. Uchida, N. Yoshioka, and K. Yamamoto, Sci. Technol. Adv. Mater., 5, 697 (2004).

26. N. G. Connelly and W. E. Geiger, Chem. Rev., 96, 877 (1996).

27. a) T. Michinobu, E. Tsuchida, and H. Nishide, Polyhedron, 20, 1147 (2001).

b) H. Murata, D. Miyajima, R. Takada, and H. Nishide, Polym. J., 37, 818 (2005). 